\title{
Kinetic properties of sodium-ion transfer at the interface between graphitic materials and organic electrolyte solutions
}

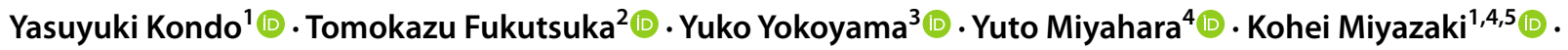 \\ Takeshi Abe ${ }^{1,4,5}$
}

Received: 18 August 2020 / Accepted: 16 December 2020 / Published online: 7 February 2021

(c) The Author(s) 2021

\begin{abstract}
Graphitic materials cannot be applied for the negative electrode of sodium-ion battery because the reversible capacities of graphite are anomalously small. To promote electrochemical sodium-ion intercalation into graphitic materials, the interfacial sodium-ion transfer reaction at the interface between graphitized carbon nanosphere (GCNS) electrode and organic electrolyte solutions was investigated. The interfacial lithium-ion transfer reaction was also evaluated for the comparison to the sodiumion transfer. From the cyclic voltammograms, both lithium-ion and sodium-ion can reversibly intercalate into/from GCNS in all of the electrolytes used here. In the Nyquist plots, the semi-circles at the high frequency region derived from the Solid Electrolyte Interphase (SEI) resistance and the semi-circles at the middle frequency region owing to the charge-transfer resistance appeared. The activation energies of both lithium-ion and sodium-ion transfer resistances were measured. The values of activation energies of the interfacial lithium-ion transfer suggested that the interfacial lithium-ion transfer was influenced by the interaction between lithium-ion and solvents, anions or SEI. The activation energies of the interfacial sodium-ion transfer were larger than the expected values of interfacial sodium-ion transfer based on the week Lewis acidity of sodiumion. In addition, the activation energies of interfacial sodium-ion transfer in dilute FEC-based electrolytes were smaller than those in concentrated electrolytes. The activation energies of the interfacial lithium/sodium-ion transfer of CNS-1100 in FEC-based electrolyte solutions were almost the same as those of CNS-2900, indicating that the mechanism of interfacial charge-transfer reaction seemed to be the same for highly graphitized materials and low-graphitized materials each other.
\end{abstract}

Yasuyuki Kondo

yasuyuki.kondo@elech.kuic.kyoto-u.ac.jp

1 Hall of Global Environmental Research, Kyoto University, Nishikyo-ku, Kyoto 615-8510, Japan

2 Graduate School of Engineering, Nagoya University, Furo-cho, Chikusa-ku, Nagoya 464-8603, Japan

3 Office of Society-Academia Collaboration for Innovation, Kyoto University, Nishikyo-ku, Kyoto 615-8510, Japan

4 Graduate School of Engineering, Kyoto University, Nishikyo-ku, Kyoto 615-8510, Japan

5 Element Strategy Initiative for Catalysts \& Batteries (ESICB), Kyoto University, Nishikyo-ku, Kyoto 615-8246, Japan 


\section{Graphic abstract}
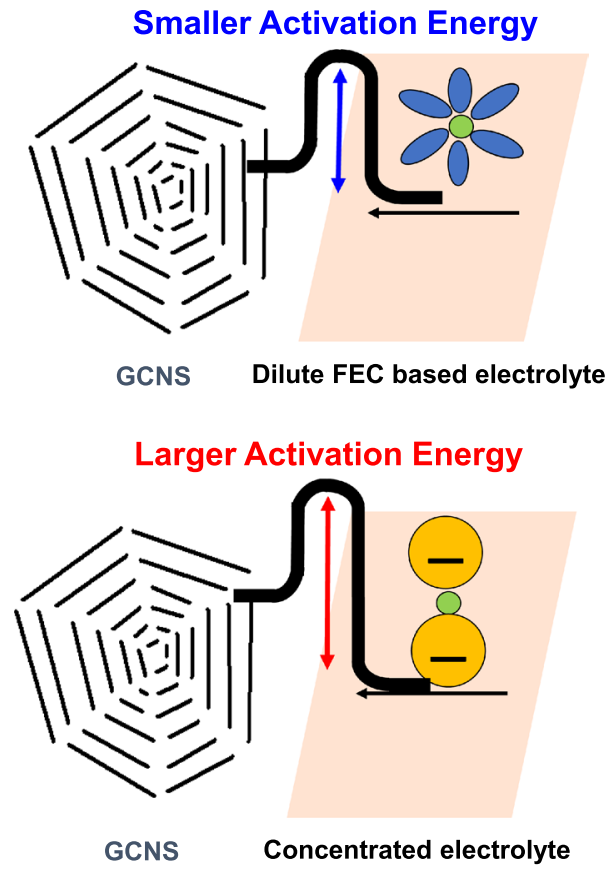

Keywords Sodium-ion battery $\cdot$ Graphite negative electrode $\cdot$ Solid Electrolyte Interphase $\cdot$ Interfacial charge-transfer resistance

\section{Introduction}

Graphite is commonly used as the negative electrode materials for lithium-ion batteries (LIBs) [1]. Graphite negative electrode is applied for LIBs even though the potential of lithium-ion intercalation into graphite is lower than the bottom limit of potential window of organic electrolyte solutions. This is because the passivation film called as Solid Electrolyte Interphase (SEI) can be formed on graphite electrodes in some organic electrolyte solutions like ethylene carbonate (EC) based electrolytes [2]. Hence, application of graphite negative electrodes contributes to fabricate the LIBs with high energy density. However, graphite is not suitable for the negative electrode material in sodium-ion batteries (SIBs). This is because the sodium-ion intercalation capacities of graphite are anomalously small mainly due to the lower theoretical sodium intercalation capacity of graphite compared to the other alkali metal intercalation capacities [3-5]. SIBs are recently studied as the post LIBs because the resources of SIBs are abundant and the cost of SIBs is expected to be lower than that of LIBs [6]. However, the energy density of SIBs is still lower than that of LIBs, and the energy density is needed to be improved for the practical application.
Our group previously studied the electrochemical reactivity between sodium-ion and graphitic materials to take the hint for the application of graphite negative electrodes. As a result, we revealed that sodium-ion diffusion distance inside graphite was very short at room temperature [7]. In addition, reversible capacities of sodium-ion intercalation into graphitic materials can be increased using graphitic materials with small particle sizes like graphitized carbon nanosphere (GCNS) [8]. Carbon nanosphere (CNS) with small particle sizes was studied for electrode materials in the lithium-ion battery for high rate-use $[9,10]$ or special capacitors $[11,12]$. However, sodium-ion still didn't intercalate into all spaces of GCNS. The diffusion coefficients of sodium-ion inside graphitic materials was also investigated, but the diffusion coefficients seemed not to be so slow. Thus, the solid-state diffusion rate should not be the main factor of the small reactivity between sodium and graphitic materials [7, 8]. Hence, as the kinetic properties of sodium-ion intercalation into GCNS, not only solid-state diffusion but also interfacial sodium-ion transfer between graphitic materials and electrolytes should be investigated to promote electrochemical sodium-ion intercalation. 
In the case of LIBs, resistances of interfacial lithiumion transfer between electrodes and electrolyte solutions have been studied for many years. The resistances of interfacial lithium-ion transfer are dominant in internal resistance of batteries at around the room temperature [13]. It was reported that the kinetics of lithium-ion transfer at the interface between negative electrodes and electrolyte solutions was influenced by the interaction between lithium-ion and solvents, counter anions or SEI in common organic electrolyte solutions, organic electrolyte solutions with film forming additives or bis(trifluoromethanesulfonyl)amide (TFSA) anion type ionic liquid based electrolyte solutions, respectively [14-16]. This tendency is also confirmed for the interfacial lithium-ion transfer at the model interface between solid electrolytes and liquid electrolytes [17]. The activation energies of sodium-ion transfer at the interface between solid electrolytes and liquid electrolytes were also reported. However, the kinetics of sodium-ion transfer was determined not by solvation ability of solvents but by interaction between sodium-ion and solid electrolytes unlike the case of interfacial lithium-ion transfer reaction [18]. In addition, the activation energies were relatively small when sodium super ionic conductor (NASICON) was used as a solid electrolyte, suggesting that the interaction between sodium-ion and organic solvents is weaker than the interaction between lithium-ion and solvents [18]. Some groups investigated the interfacial sodium-ion transfer reaction between positive electrodes and electrolytes [19, 20]. In these reports, the activation energies of sodium-ion transfer resistances were sometimes as large as those of lithium-ion transfer resistances. However, the reason of larger activation energies of sodium-ion transfer resistances between electrodes and electrolytes than those between solid electrolyte and liquid electrolyte was still unclear and there was no clear consensus about the mechanism of interfacial sodium-ion transfer reaction. In addition, interfacial sodium-ion transfer reaction at the interface between graphitic materials and electrolyte solutions have not been studied well.

In this study, the activation energies of sodium-ion transfer at the interface between GCNS and organic electrolyte solutions were investigated to reveal the kinetic properties of the interfacial sodium-ion transfer reaction. EC-based electrolytes with high concentration and fluoroethylene carbonate (FEC) based electrolytes were used to make stable SEI because stable SEI is necessary to conduct the electrochemical impedance spectroscopy. As the comparison, interfacial lithium-ion transfer reaction at the interface between GCNS electrode and organic electrolyte solutions were investigated beforehand. In addition, the effect of the structural difference of CNSs prepared at different temperature for interfacial lithium/sodium-ion transfer reaction was also investigated because the defects in the graphitic materials [21, 22] and the gaps between graphene layers inside graphitic materials
$[23,24]$ influence the diffusion of lithium/sodium-ion. Our group previously reported that the sodium-ion insertion and diffusion inside CNSs seemed to be promoted using CNSs treated at low temperature due to the defects and large interlayer distances [8]. In this study, we focused on the interfacial lithium/sodium-ion transfer reaction using CNSs prepared at different temperature.

\section{Experimental}

Electrochemical measurements were carried out using a three-electrode cell. A carbon nanosphere [9] composite electrode (CNS (700-800 nm, Tokai carbon Co., Ltd.) : Polyvinylidene difluoride $=8: 2$ ) was used as a working electrode. CNS was treated at $2900{ }^{\circ} \mathrm{C}$ and $1100{ }^{\circ} \mathrm{C}$ and denoted as CNS-2900 and CNS-1100, respectively. For sodium system, $\mathrm{Ag} / \mathrm{Ag}^{+}$electrode (silver wire immersed into $\mathrm{EC}+$ dimethyl carbonate $(\mathrm{DMC})(1: 1$ by vol.) (Kishida Chemical Co., Ltd.) mixture containing $0.2 \mathrm{~mol} \mathrm{~kg}^{-1}$ sodium bis(trifluoromethanesulfonyl)amide (NaTFSA, Kishida Chemical Co., Ltd.) and $0.04 \mathrm{~mol} \mathrm{~kg}^{-1}$ silver trifluoromethanesulfonate (Sigma Aldrich)) was used as a reference electrode and a natural graphite composite electrode (natural graphite:Polyvinylidene difluoride $=9: 1$ ) was used as a counter electrode. For lithium system, lithium metals were used as reference and counter electrodes. Electrolyte solutions for sodium systems were fluoroethylene carbonate (FEC) (Tomiyama Pure Chemical Industries) containing $0.7 \mathrm{~mol} \mathrm{~kg}^{-1} \mathrm{NaTFSA}$ and EC + DMC (1:1 by vol.) (Kishida Chemical Co., Ltd.) mixture containing $4 \mathrm{~mol} \mathrm{~kg}^{-1}$ NaTFSA. Electrolyte solutions for lithium systems were FEC containing $0.7 \mathrm{~mol} \mathrm{~kg}^{-1}$ lithium bis(trifluoromethanesulfonyl)amide (LiTFSA, Kishida Chemical Co., Ltd.) and EC + DMC (1:1 by vol.) mixture containing 0.9 or $4 \mathrm{~mol} \mathrm{~kg}^{-1}$ LiTFSA. The potentials of silver reference electrodes in sodium systems were calibrated by measuring the redox potential of ferrocene in each electrolyte containing $3 \mathrm{mmol} \mathrm{kg}^{-1}$ ferrocene (Alfa Aesar). Hereafter, all potentials in sodium systems and in lithium systems are referred to as $\mathrm{Fc} / \mathrm{Fc}^{+}$ and $\mathrm{Li} / \mathrm{Li}^{+}$, respectively. Cyclic voltammetry $(\mathrm{CV})$ was conducted between open circuit potential (OCV) and various potentials, and the scan rate was set at $0.1 \mathrm{mV} \mathrm{s}^{-1}$. Electrochemical impedance spectroscopy (EIS) was carried out with ac amplitude of $10 \mathrm{mV}$ in a frequency range of $100 \mathrm{kHz}-1 \mathrm{MHz}$ at various temperatures ranging from 30 to $10{ }^{\circ} \mathrm{C}$. The cells were assembled in an Arfilled glove box. All electrochemical measurements were carried out using HSV-100 (HOKUTO-DENKO) and Solartron 1470E + 1400A (Solartron Analytical). Scanning electron microscope (SEM) and X-ray diffraction (XRD) were used for structural characterization of CNSs 
using S-3000H (Hitachi High-Tech Fielding Corp.) and RINT2200 (RIGAKU).

\section{Results and discussion}

\subsection{Structural characterization of CNSs}

Figure 1 shows the XRD patterns of CNS-2900 and CNS1100. From the XRD patterns, CNS-2900 had the highly graphitized structure with the sharp 002 line. Interlayer distance of graphene layers $\left(d_{002}\right), L_{a}$, and $L_{c}$ in CNS-2900 were reported to be $0.338 \mathrm{~nm}, 68 \mathrm{~nm}$ and $37 \mathrm{~nm}$, respectively [9]. On the other hand, CNS-1100 didn't have 002 line clearly, and had the amorphous and low-graphitized structure. Figure 2 shows the SEM images of CNS-2900 and CNS-1100 composite electrodes. CNS-2900 had the polygon shape covered with highly graphitized basal planes as previously reported in the literature $[9,10]$. Previously, the existence of edge plane at the corner of GCNS

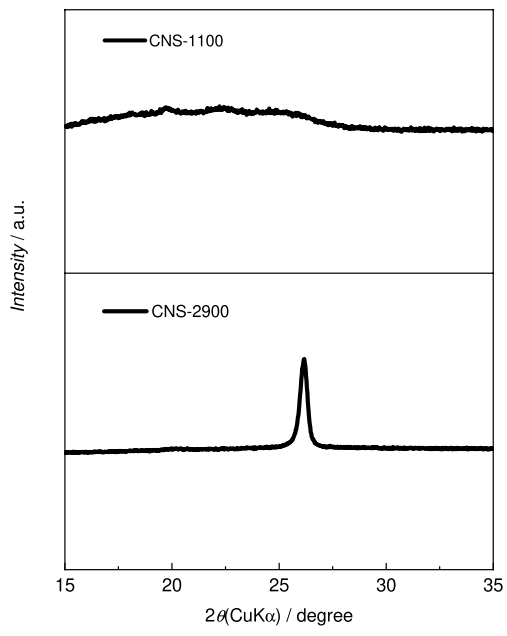

Fig. 1 XRD patterns of a CNS-2900 and b CNS-1100 composite electrodes was reported from TEM images [9, 10]. Hence, lithium/ sodium-ion can intercalate into CNS-2900 mainly from the edge plane at the corner. CNS-1100 had the spherical shape indicating the coverage by bent basal planes derived from low graphitization degree, and lithium/sodium-ion intercalates into CNS-1100 from the surface of CNS-1100.

\subsection{Lithium-ion transfer reaction at the interface between GCNS composite electrodes/organic electrolyte solutions}

Firstly, electrochemical properties of CNS-2900 composite electrodes in electrolytes containing lithium-ion were investigated. Figure 3 shows the CVs of CNS-2900 composite electrodes in 0.9 and $4 \mathrm{~mol} \mathrm{~kg}^{-1}$ LiTFSA/ EC+DMC(1:1 by vol.) and $0.7 \mathrm{~mol} \mathrm{~kg}^{-1}$ LiTFSA/FEC. The irreversible currents were observed only in the first cycle, suggesting the formation of SEI on GCNS electrodes in all of electrolytes. The redox peaks also appeared in all of the electrolytes, and were assigned to the reversible lithium-ion insertion into/from CNS-2900.

Figure 4 shows the Nyquist plots of CNS-2900 composite electrode in 0.9 and $4 \mathrm{~mol} \mathrm{~kg}^{-1}$ LiTFSA/EC+DMC $(1: 1$ by vol.) and $0.7 \mathrm{~mol} \mathrm{~kg}^{-1}$ LiTFSA/FEC. Two semi-circles appeared at the high frequency and the middle frequency regions in $0.9 \mathrm{~mol} \mathrm{~kg}^{-1}$ LiTFSA/EC+DMC(1:1 by vol.) and $0.7 \mathrm{~mol} \mathrm{~kg}^{-1}$ LiTFSA/FEC at $0.8-0.2 \mathrm{~V}$ vs. $\mathrm{Li}^{2} / \mathrm{Li}^{+}$. The semi-circles at the high frequency region were independent on the potential of electrodes, but the semi-circles at the middle frequency region were dependent on the potential. In the study of highly oriented pyrolytic graphite (HOPG) model electrodes, the semi-circles at the middle frequency region were assigned to lithiumion transfer resistance based on the potential dependence [25]. Hence, the semi-circles at the high frequency region and at the middle frequency region were mainly assigned to SEI resistance and charge-transfer resistance, respectively. The capacitances of lithium-ion transfer resistances of CNS-2900 electrodes seemed to be around $0.5 \mathrm{mF}$ by
Fig. 2 SEM images of a CNS2900 and b CNS-1100 composite electrodes
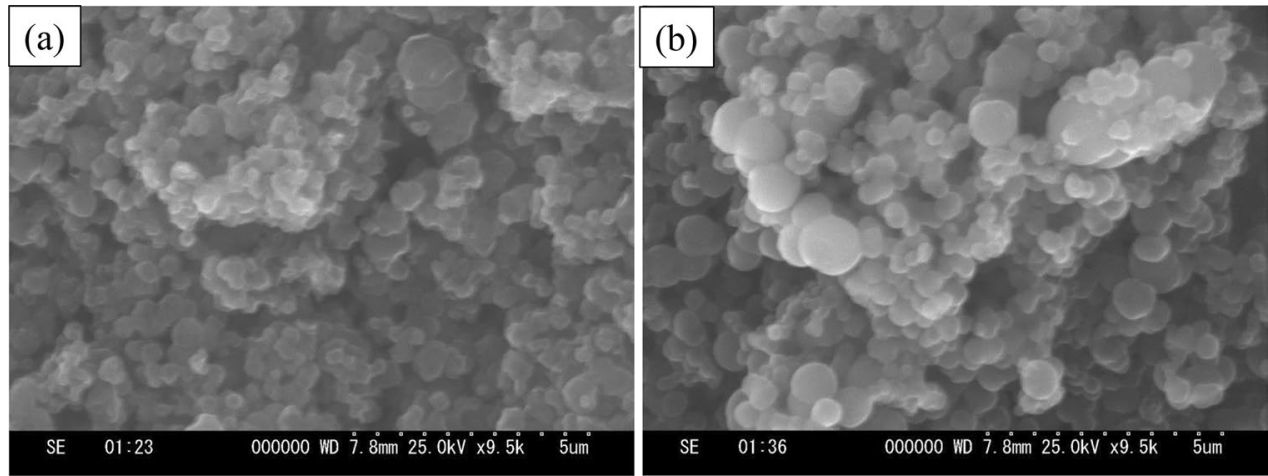

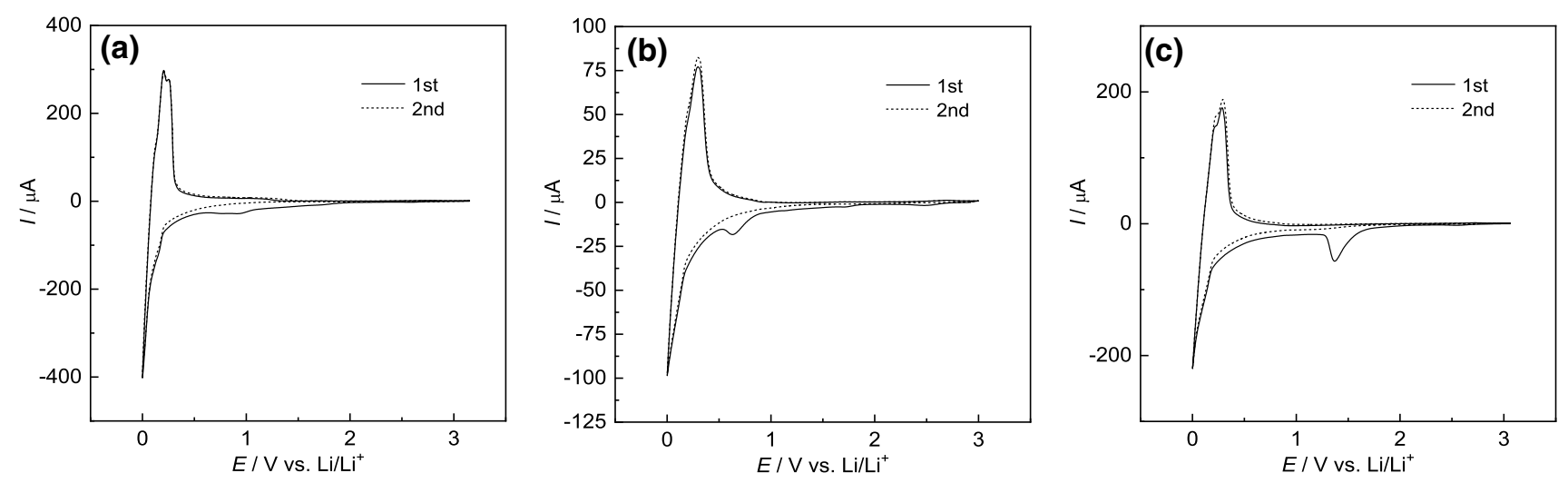

Fig. 3 Cyclic voltammograms of CNS-2900 composite electrode in a 0.9 , b $4 \mathrm{~mol} \mathrm{~kg}^{-1}$ LiTFSA/EC+DMC(1:1 by vol.) and c $0.7 \mathrm{~mol} \mathrm{~kg}^{-1}$ LiTFSA/FEC at a scan rate of $0.1 \mathrm{mV} \mathrm{s}^{-1}$
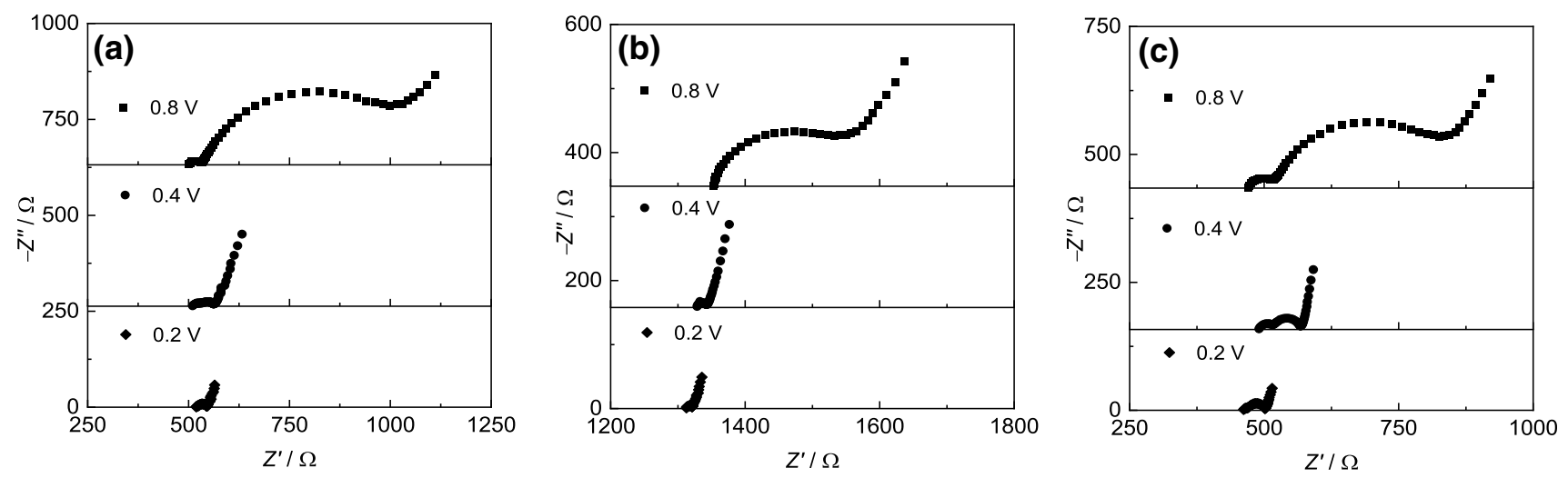

Fig. 4 Nyquist plots of CNS-2900 composite electrode in a 0.9, b $4 \mathrm{~mol} \mathrm{~kg}^{-1}$ LiTFSA/EC+DMC(1:1 by vol.) and $\mathbf{c} 0.7 \mathrm{~mol} \mathrm{~kg}{ }^{-1} \mathrm{LiTFSA} / \mathrm{FEC}$

the fitting of Nyquist plots. In addition, after conducting cyclic voltammetry, only the semi-circle at the high frequency was observed at open circuit potential, where lithium-ion intercalation reaction didn't proceed, suggesting that the semi-circle at the high frequency region is mainly derived from the existence of SEI. In these Nyquist plots, the straight line at the high frequency region derived from ionic resistances in pours of composite electrodes [13] was not clearly observed, indicating that the ionic resistances were negligible in our study. Only one semi-circle was observed at the middle frequency region in $4 \mathrm{~mol} \mathrm{~kg}^{-1}$ LiTFSA/EC+DMC(1:1 by vol.) at $0.8-0.2 \mathrm{~V}$ vs. $\mathrm{Li} / \mathrm{Li}^{+}$. As for the concentrated electrolytes, this semi-circle was mainly assigned to charge-transfer resistance based on the potential dependence. The SEI resistance seemed to be negligible in this concentrated electrolyte. This is probably because the SEI in the concentrated electrolyte is more stable than in $0.9 \mathrm{~mol} \mathrm{~kg}^{-1}$ LiTFSA/EC+DMC $(1: 1$ by vol.) and the passivation by the SEI formation might be minimized.
The activation energies of interfacial lithium-ion transfer resistances at the interface between GCNS and electrolyte solutions were investigated. Figure 5 shows the temperature dependence of charge-transfer resistances of CNS2900 composite electrodes in 0.9 and $4 \mathrm{~mol} \mathrm{~kg}^{-1}$ LiTFSA/ EC+DMC(1:1 by vol.) and $0.7 \mathrm{~mol} \mathrm{~kg}^{-1}$ LiTFSA/FEC. The activation energy in $0.9 \mathrm{~mol} \mathrm{~kg}^{-1}$ LiTFSA/EC+DMC $(1: 1$ by vol.) was $49-60 \mathrm{~kJ} \mathrm{~mol}^{-1}$, suggesting the rate determining step was de-solvation process like the case of HOPG [25]. The activation energy in $4 \mathrm{~mol} \mathrm{~kg}^{-1}$ LiTFSA/EC+DMC $(1: 1$ by vol.) was $66-71 \mathrm{~kJ} \mathrm{~mol}^{-1}$ and very large. It indicated that the kinetics of interfacial lithium-ion transfer reaction in concentrated electrolytes was controlled by the interaction between lithium-ion and anion. Lastly, the activation energy in $0.7 \mathrm{~mol} \mathrm{~kg}^{-1}$ LiTFSA/FEC was $53-59 \mathrm{~kJ} \mathrm{~mol}^{-1}$. This value was much larger than the activation energy of interfacial lithium-ion transfer resistance at the interface between FEC-based electrolyte solution and solid electrolyte $\left(31.5 \mathrm{~kJ} \mathrm{~mol}^{-1}\right)$ [17]. Hence, this activation energy was not derived from the de-solvation of FEC. After forming 

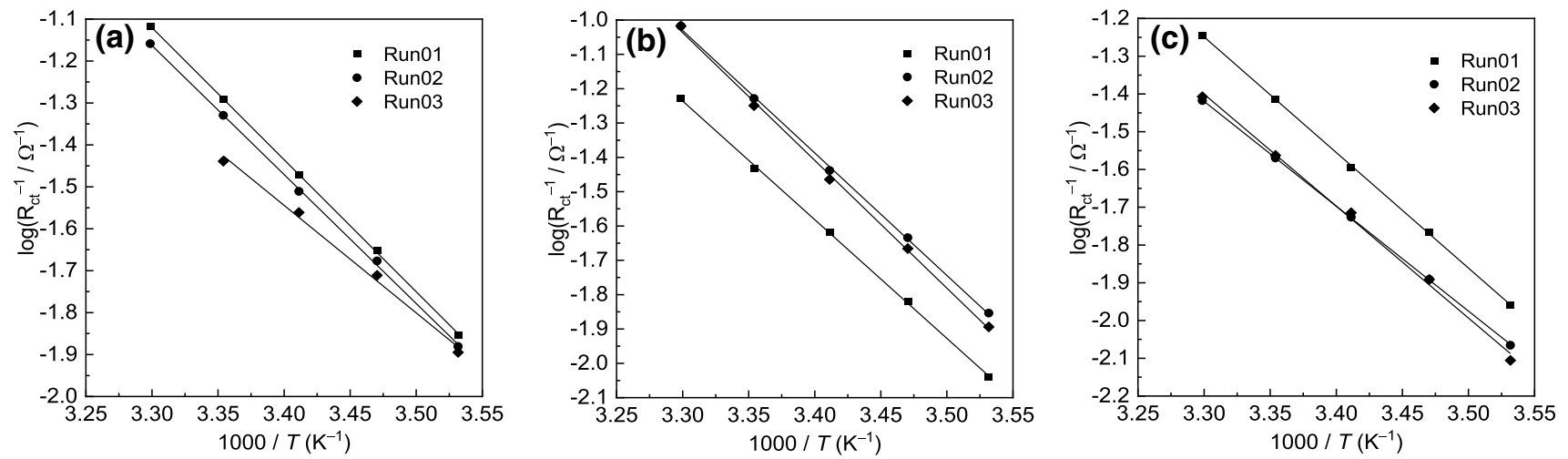

Fig. 5 Temperature dependence of charge-transfer resistances of CNS-2900 composite electrodes in a $0.9, \mathbf{b}^{4} \mathrm{~mol} \mathrm{~kg}^{-1} \mathrm{LiTFSA}_{\mathrm{EC}}+\mathrm{DMC}(1: 1$ by vol.) and $\mathbf{c} 0.7 \mathrm{~mol} \mathrm{~kg} \mathrm{ki}^{-1}$ LiTFSA/FEC

SEI on graphite electrode in electrolyte solutions containing electrolyte additives, the activation energy of lithiumion transfer resistance at the interface between graphite and electrolyte solutions was determined by the interaction between lithium-ion and SEI. [16] Based on this report, the activation energy in FEC-based electrolytes also seemed to be determined by the interaction between lithium-ion and FEC derived SEI. These results were consistent with the previous reports of graphite [14-16], which means the accuracy of calculating activation energies using these composite electrodes was enough.

\subsection{Sodium-ion transfer reaction at the interface between CNS composite electrodes/organic electrolyte solutions}

Figure 6 shows the CVs of CNS-2900 composite electrodes in $4 \mathrm{~mol} \mathrm{~kg}^{-1} \mathrm{NaTFSA} / \mathrm{EC}+\mathrm{DMC}(1: 1$ by vol.) and $0.7 \mathrm{~mol} \mathrm{~kg}^{-1}$ NaTFSA/FEC. The irreversible currents were observed in all of the electrolytes, and most of the irreversible currents disappeared after the 2nd cycle, indicating the formation of SEI on CNS electrodes at the same manner of lithium-ion system. Compared with the dilute EC-based electrolyte [8], concentrated EC-based electrolytes and FEC-based electrolytes formed the SEI with higher stability because the coulombic efficiencies of these electrolytes were better than that of the dilute EC-based electrolytes. The redox peaks also appeared in these electrolytes, and were assigned to the reversible sodium-ion insertion into/ from CNS-2900.

Figure 7 shows the Nyquist plots of CNS-2900 composite electrode in $4 \mathrm{~mol} \mathrm{~kg}^{-1} \mathrm{NaTFSA} / \mathrm{EC}+\mathrm{DMC}(1: 1$ by vol.) and $0.7 \mathrm{~mol} \mathrm{~kg}^{-1} \mathrm{NaTFSA} / F E C$. Only one semi-circle appeared at the middle frequency region in $4 \mathrm{~mol} \mathrm{~kg}^{-1}$ NaTFSA/EC+DMC (1:1 by vol.) and $0.7 \mathrm{~mol} \mathrm{~kg}^{-1}$ NaTFSA/FEC. This semi-circle at the middle frequency region was assigned to the charge-transfer resistance like the case of other carbon negative electrodes [26]. The SEI resistance seemed to be negligible in these electrolytes. In this study, dilute EC-based electrolyte was not examined because the impedance measurement couldn't be conducted properly by the instability of SEI. The capacitances
Fig. 6 Cyclic voltammograms of CNS-2900 composite electrode in a $4 \mathrm{~mol} \mathrm{~kg}^{-1} \mathrm{NaTFSA} /$ $\mathrm{EC}+\mathrm{DMC}(1: 1$ by vol.) and $\mathbf{b}$ $0.7 \mathrm{~mol} \mathrm{~kg}^{-1} \mathrm{NaTFSA} / \mathrm{FEC}$ at a scan rate of $0.1 \mathrm{mV} \mathrm{s}^{-1}$
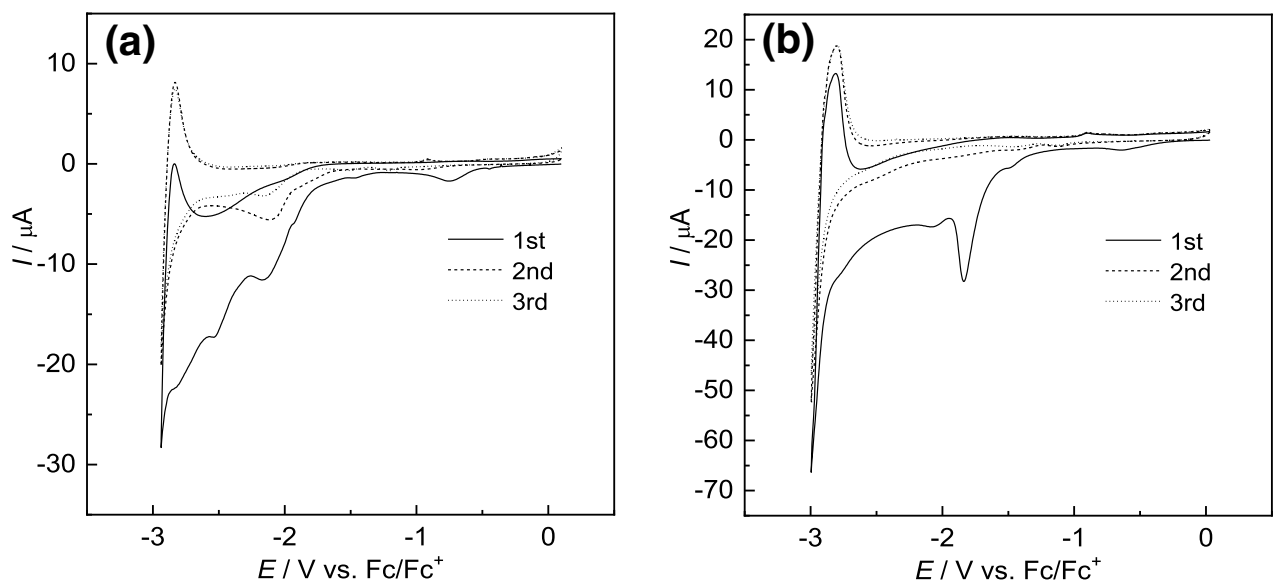
Fig. 7 Nyquist plots of CNS2900 composite electrode in a $4 \mathrm{~mol} \mathrm{~kg}^{-1} \mathrm{NaTFSA} /$ $\mathrm{EC}+\mathrm{DMC}(1: 1$ by vol.) and $\mathbf{b}$ $0.7 \mathrm{~mol} \mathrm{~kg}^{-1} \mathrm{NaTFSA} / \mathrm{FEC}$

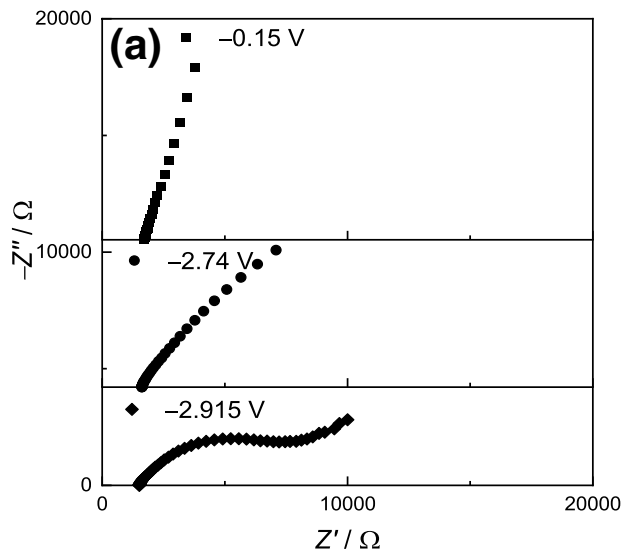

of sodium-ion transfer resistances of CNS-2900 electrodes seemed to be around $0.1 \mathrm{mF}$ by the fitting of Nyquist plots. These values were smaller than the capacitances of lithium system.

Next, the activation energies of interfacial sodium-ion transfer resistances at the interface between GCNS and electrolyte solutions were investigated. Figure 8 shows the temperature dependence of charge-transfer reactions of CNS-2900 composite electrodes in $4 \mathrm{~mol} \mathrm{~kg}^{-1}$ NaTFSA/ EC+DMC(1:1 by vol.) and $0.7 \mathrm{~mol} \mathrm{~kg}^{-1} \mathrm{NaTFSA} / \mathrm{FEC}$. The activation energy in $4 \mathrm{~mol} \mathrm{~kg}^{-1} \mathrm{NaTFSA} / \mathrm{EC}+\mathrm{DMC}(1: 1$ by vol.) was $73-76 \mathrm{~kJ} \mathrm{~mol}^{-1}$ and very large. The activation energy in $0.7 \mathrm{~mol} \mathrm{~kg}^{-1} \mathrm{NaTFSA} / \mathrm{FEC}$ was $54-61 \mathrm{~kJ} \mathrm{~mol}^{-1}$. These values seemed to be almost equivalent to the values of interfacial lithium-ion transfer and much larger than the expected activation energies of interfacial sodium-ion transfer resistance determined by the interaction between sodium-ion as weak Lewis acid and solvent or anion, etc., as Lewis base. The reason for the large activation energies of interfacial sodium-ion transfer resistance might be the higher energy of the transition state compared with interfacial lithium-ion transfer. In addition, the activation energy in concentrated electrolytes was larger than the activation energies in dilute FEC-based electrolytes. These results mean that the activation energies of interfacial sodium-ion transfer resistances at the interface between GCNSs and electrolyte solutions are different from the case of model interface and influenced by the composition of electrolytes. Based on these results, not concentrated electrolytes but dilute FEC-based electrolytes seemed to be desirable to promote sodium-ion intercalation into graphitic materials from the view of activation energies. The reason for the larger activation energy in concentrated electrolytes might be the large interaction between sodium-ion and anion or the much higher energy of the transition state. The energy of the transition state might increase by the influence of SEI or the structural influence of CNSs.

\subsection{Lithium/sodium-ion transfer reaction at the interface between low crystallized CNS composite electrodes/organic electrolyte solutions}

Finally, electrochemical properties of CNS-1100 composite electrodes in FEC-based electrolytes containing lithium/ sodium-ion were investigated because CNS-2900 composite
Fig. 8 Temperature dependence of charge-transfer resistances of CNS-2900 composite electrodes in a $4 \mathrm{~mol} \mathrm{~kg}^{-1}$ NaTFSA/ $\mathrm{EC}+\mathrm{DMC}(1: 1$ by vol. $)$ and $\mathbf{b}$ $0.7 \mathrm{~mol} \mathrm{~kg}^{-1}$ NaTFSA/FEC
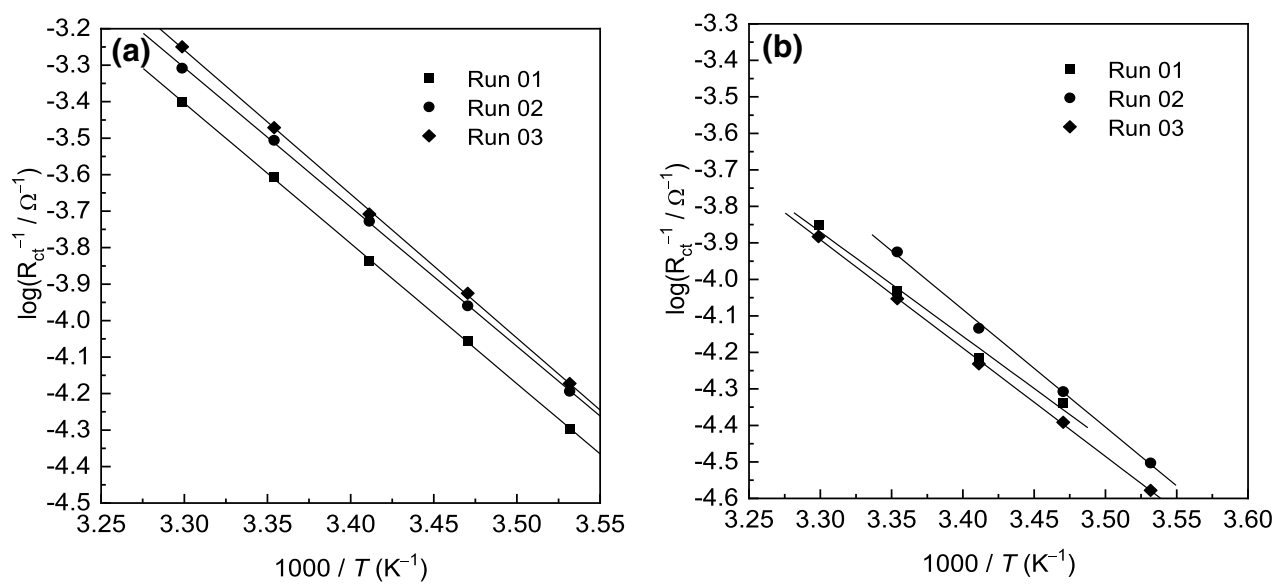
Fig. 9 Cyclic voltammograms of CNS-1100 composite electrode in a $0.7 \mathrm{~mol} \mathrm{~kg}^{-1}$ LiTFSA/ FEC and $\mathbf{b} 0.7 \mathrm{~mol} \mathrm{~kg}^{-1}$

NaTFSA/FEC at a scan rate of $0.1 \mathrm{mV} \mathrm{s}^{-1}$

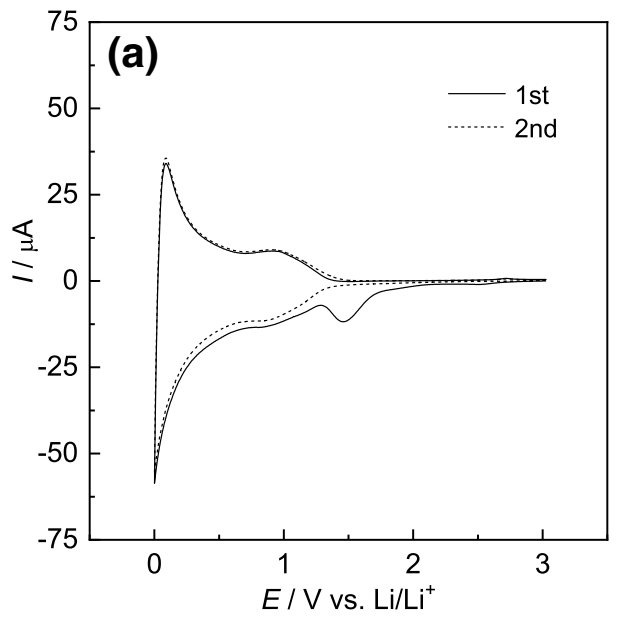

electrodes showed relatively small activation energies for both lithium and sodium systems in FEC-based electrolyte solutions. Figure 9 shows the CVs of CNS-2900 composite electrodes in $0.7 \mathrm{~mol} \mathrm{~kg}^{-1}$ LiTFSA/FEC and $0.7 \mathrm{~mol} \mathrm{~kg}-1$ NaTFSA/FEC. The redox peaks clearly appeared at low potentials near the redox potentials of lithium/sodium metals in both FEC-based electrolytes, and were assigned to the reversible lithium/sodium-ion insertion into/from CNS-1100.

Figure 10 shows the Nyquist plots of CNS- 1100 composite electrode in $0.7 \mathrm{~mol} \mathrm{~kg}^{-1}$ LiTFSA/FEC and $0.7 \mathrm{~mol} \mathrm{~kg}^{-1}$ NaTFSA/FEC. The semi-circles at the middle frequency region were mainly assigned to charge-transfer resistance like the case of CNS-2900. The capacitances of lithium and sodium-ion transfer resistances of CNS-1100 electrodes seemed to be around $0.1 \mathrm{mF}$ and $0.05 \mathrm{mF}$ by the fitting of Nyquist plots, respectively. These values were smaller than those of CNS-2900. Figure 11 shows the temperature dependence of charge-transfer reactions of CNS-1100 composite electrodes in $0.7 \mathrm{~mol} \mathrm{~kg}^{-1}$ LiTFSA/FEC and
$0.7 \mathrm{~mol} \mathrm{~kg}^{-1} \mathrm{NaTFSA} / \mathrm{FEC}$. The activation energy for CNS1100 in $0.7 \mathrm{~mol} \mathrm{~kg}^{-1} \mathrm{LiTFSA} / \mathrm{FEC}$ was $51 \mathrm{~kJ} \mathrm{~mol}^{-1}$ and near the value of activation energy for CNS-2900. The activation energy in $0.7 \mathrm{~mol} \mathrm{~kg}^{-1} \mathrm{NaTFSA} / \mathrm{FEC}$ was $60-63 \mathrm{~kJ} \mathrm{~mol}^{-1}$ and also near the value of activation energy for CNS-2900. These values indicated that the activation energies of lithium/sodium-ion transfer resistances seem not to be dependent on the graphitization degree unlike the cases of solidstate diffusion inside graphitic materials. Therefore, the rate determining step of interfacial lithium-ion transfer reaction of CNS-1100 seemed to be the same as that of CNS-2900. In addition, the energy of transition state in interfacial sodiumion transfer reaction might be influenced by SEI resulting in the larger activation energies of interfacial sodium-ion transfer resistance than the expected values based on the simple interaction between sodium-ion and solvents or anions.
Fig. 10 Nyquist plots of CNS1100 composite electrode in a $0.7 \mathrm{~mol} \mathrm{~kg}^{-1}$ LiTFSA/FEC and b $0.7 \mathrm{~mol} \mathrm{~kg}^{-1} \mathrm{NaTFSA} / \mathrm{FEC}$
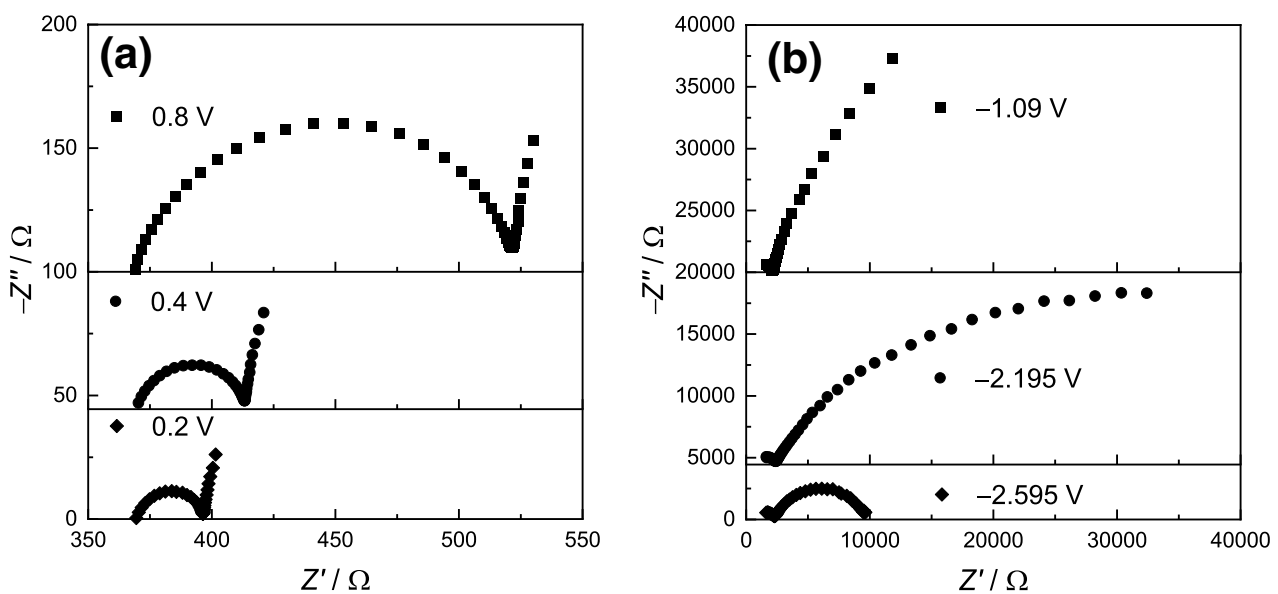
Fig. 11 Temperature dependence of charge-transfer resistances of CNS-1100 composite electrodes in a $0.7 \mathrm{~mol} \mathrm{~kg}^{-1}$ LiTFSA/FEC and b $0.7 \mathrm{~mol} \mathrm{~kg}^{-1} \mathrm{NaTFSA} / \mathrm{FEC}$
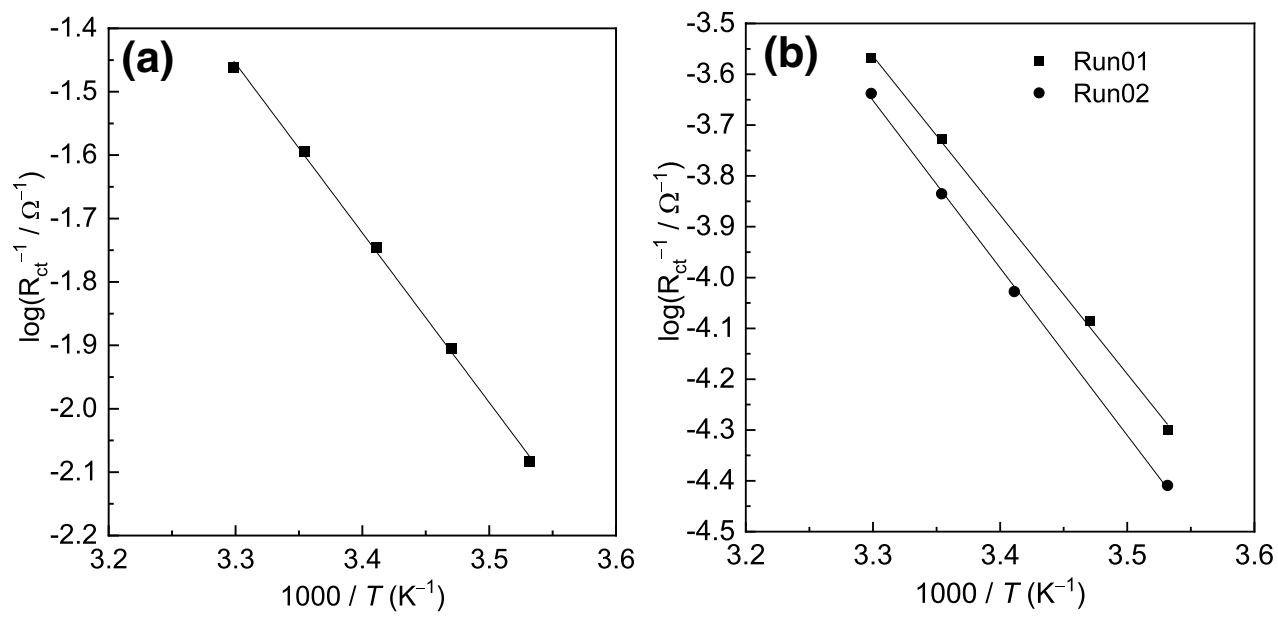

\section{Conclusion}

The interfacial lithium-ion and sodium-ion transfer reaction at the interface between CNS-2900 or CNS-1100 electrodes and electrolyte solutions were investigated. From the cyclic voltammograms, both lithium/sodium-ion intercalation into/ from CNS-2900 can proceed in all of the electrolytes. In the Nyquist plots, the semi-circles at the high frequency region derived from the SEI resistance and the semi-circles at the middle frequency region owing to the charge-transfer resistance appeared. The values of activation energies of the interfacial lithium-ion transfer suggested that the interfacial lithium-ion transfer was influenced by the interaction between lithium-ion and solvents, anions or SEI like the case of model carbon electrodes. The activation energies of the interfacial sodium-ion transfer were different from the activation energies of interfacial sodium-ion transfer at the model solid electrolyte/liquid electrolyte. The activation energies of the interfacial lithium/sodium-ion transfer of CNS-1100 in FEC-based electrolyte solutions were almost the same as those of CNS-2900.

Acknowledgements This work was partially supported by ESICB, Kyoto University.

\section{Compliance with ethical standards}

Conflict of interest All authors declare that they have no conflict of interest.

Open Access This article is licensed under a Creative Commons Attribution 4.0 International License, which permits use, sharing, adaptation, distribution and reproduction in any medium or format, as long as you give appropriate credit to the original author(s) and the source, provide a link to the Creative Commons licence, and indicate if changes were made. The images or other third party material in this article are included in the article's Creative Commons licence, unless indicated otherwise in a credit line to the material. If material is not included in the article's Creative Commons licence and your intended use is not permitted by statutory regulation or exceeds the permitted use, you will need to obtain permission directly from the copyright holder. To view a copy of this licence, visit http://creativecommons.org/licenses/by/4.0/.

\section{References}

1. Ogumi Z, Inaba M (1998) Electrochemical lithium intercalation within carbonaceous materials: intercalation processes, surface film formation, and lithium diffusion. Bull Chem Soc Jpn 71:521-534. https://doi.org/10.1246/bcsj.71.521

2. Besenhard JO, Winter M, Yang J, Biberacher W (1995) Filming mechanism of lithium-carbon anodes in organic and inorganic electrolytes. J Power Sources 54:228-231. https://doi.org/10.1016/03787753(94)02073-C

3. Qi S, Li F, Wang J, Yuanyuan Qu, Yang Y, Li W, Zhao M (2019) Prediction of a flexible anode material for $\mathrm{Li} / \mathrm{Na}$ ion batteries: phosphorous carbide monolayer (a-PC). Carbon 141:444-450. https:// doi.org/10.1016/j.carbon.2018.09.031

4. Li NN, Sheng ZM, Huang H, Gan ZZ, Chang CK, Jia RP, Han $\mathrm{S}$ (2019) $\mathrm{Fe}_{2} \mathrm{O}_{3}$ nanoparticles encapsulated with $\mathrm{N}$-doped porous graphitic shells approached by oxidizing $\mathrm{Fe}_{3} \mathrm{C} @ \mathrm{C}$ precursor for high performance sodium-ion batteries. J Alloys Compd 792:25-31. https ://doi.org/10.1016/j.jallcom.2019.04.008

5. Li NN, Sheng ZM, Huang H, Gan ZZ, Chang CK, Jia RP, Han S (2018) In situ approach of cementite nanoparticles encapsulated with nitrogen-doped graphitic shells as anode nanomaterials for Li-ion and Na-ion batteries. RSC Adv 8:33030-33034. https://doi. org/10.1039/C8RA05544K

6. Komaba S, Murata W, Ishikawa T, Yabuuchi N, Ozeki T, Nakayama T, Ogata A, Gotoh K, Fujiwara K (2011) Electrochemical Na insertion and solid electrolyte interphase for hard-carbon electrodes and application to Na-ion batteries. Adv Funct Mater 21:3859-3867. https://doi.org/10.1002/adfm.201100854

7. Kondo Y, Fukutsuka T, Miyazaki K, Miyahara Y, Abe T (2019) Investigation of electrochemical sodium-ion intercalation behavior into graphite-based electrodes. J Electrochem Soc 166:A5323A5327. https://doi.org/10.1149/2.0431903jes

8. Kondo Y, Fukutsuka T, Miyazaki K, Miyahara Y, Abe T (2019) Sodium-ion intercalation behavior of graphitized carbon nanospheres covered with basal plane. Chem Lett 48:799-801. https:// doi.org/10.1246/cl.190111

9. Yoshizawa N, Soneda Y, Hatori H, Ue H, Abe T (2010) Development and degradation of graphitic microtexture in carbon nanospheres under a morphologically restrained condition. Mater 
Chem Phys 121:419-424. https://doi.org/10.1016/j.matchemphy s.2010.01.054

10. Yoshizawa N, Tanaike O, Hatori H, Yoshizawa K, Kondo A, Abe T (2006) TEM and electron tomography studies of carbon nanospheres for lithium secondary batteries. Carbon 44:2558-2564. https://doi. org/10.1016/j.carbon.2006.05.041

11. Lee W-H, Moon JH (2014) Monodispersed N-doped carbon nanospheres for supercapacitor application. ACS Appl Mater Interfaces 6:13968-13976. https://doi.org/10.1021/am5033378

12. Peng H, Ma G, Sun K, Mu J, Zhou X, Lei Z (2015) A novel fabrication of nitrogen-containing carbon nanospheres with high rate capability as electrode materials for supercapacitors. RSC Adv 5:12034-12042. https://doi.org/10.1039/C4RA11889H

13. Ogihara N, Kawauchi S, Okuda C, Itou Y, Takeuchi Y, Ukyo Y (2012) Theoretical and experimental analysis of porous electrodes for lithium-ion batteries by electrochemical impedance spectroscopy using a symmetric cell. J Electrochem Soc 159:A1034-A1039. https ://doi.org/10.1149/2.057207jes

14. Fukutsuka T, Sagane F, Miyazaki K, Abe T, Toda T, Matsuo Y, Sugie Y, Ogumi Z (2010) Ion-solvent interaction for lithium-ion transfer at the interface between carbonaceous thin-film electrode and electrolyte. TANSO 245:188-191. https://doi.org/10.7209/tanso 2010.188

15. Ishihara Y, Miyazaki K, Fukutsuka T, Abe T (2014) Lithium-ion transfer at the interface between high potential negative electrodes and ionic liquids. J Electrochem Soc 161:A1939-A1942. https://doi. org/10.1149/2.1111412jes

16. Yamada Y, Iriyama Y, Abe T, Ogumi Z (2009) Kinetics of lithium ion transfer at the interface between graphite and liquid electrolytes: effects of solvent and surface film. Langmuir 25:12766-12770. https ://doi.org/10.1021/la901829v

17. Abe T, Sagane F, Ohtsuka F, Iriyama Y, Ogumi Z (2005) Lithiumion transfer at the interface between lithium-ion conductive ceramic electrolyte and liquid electrolyte-a key to enhancing the rate capability of lithium-ion batteries. J Electrochem Soc 152:A2151-A2154. https://doi.org/10.1149/1.2042907

18. Sagane F, Abe T, Ogumi Z (2010) Sodium-ion transfer at the interface between ceramic and organic electrolytes. J Power Sources 195:7466-7470. https://doi.org/10.1016/j.jpowsour.2010.04.054
19. Mizuno Y, Okubo M, Hosono E, Kudo T, Zhou H, Oh-ishi K (2013) Suppressed activation energy for interfacial charge transfer of a prussian blue analog thin film electrode with hydrated ions $\left(\mathrm{Li}^{+}\right.$, $\mathrm{Na}^{+}$, and $\mathrm{Mg}^{2+}$ ). J Phys Chem C 117:10877-10882. https://doi. org/10.1021/jp311616s

20. Browning KL, Sacci RL, Veith GM (2017) Energetics of $\mathrm{Na}^{+}$ transport through the electrode/cathode interface in single solvent electrolytes. J Electrochem Soc 164:A580-A586. https://doi. org/10.1149/2.0311704jes

21. Sheng ZM, Chang XJ, Chen YH, Hong CY, Li NN, Chang CK, Jia RP, Han S (2016) Thin-walled graphitic nanocages with nitrogendoping as superior performance anodes for lithium-ion batteries $\dagger$. RSC Adv 6:59896-59899. https://doi.org/10.1039/C6RA10803B

22. Hong CY, Sheng ZM, Hu MH, Dai XY, Chang CK, Chen QZ, Zhang DY (2016) Doping-template approach of porous-walled graphitic nanocages for superior performance anodes of lithium ion batteries. RSC Adv 7:42083-42087. https://doi.org/10.1039/C7RA07859E

23. Gan ZZ, Sheng ZM, Huang H, Dai XY, Niu RL, Jia RP (2019) Highly mesoporous $\mathrm{Fe}$ and $\mathrm{N}$ Co-doped graphitic catalysts prepared from short-time synthesis of precursor towards highly efficient oxygen reduction. Sustain Energy Fuels 3:3335-3343. https://doi. org/10.1039/C9SE00532C

24. Sheng ZM, Gan ZZ, Huang H, Niu RL, Han ZW, Jia RP (2020) $\mathrm{M}-\mathrm{Nx}(\mathrm{M}=\mathrm{Fe} \mathrm{Co}, \mathrm{Ni}, \mathrm{Cu})$ doped graphitic nanocages with high specific surface area for non-enzymatic electrochemical detection of H2O2. Sens Actuators B 305:127550-127558. https://doi. org/10.1016/j.snb.2019.127550

25. Abe T, Fukuda H, Iriyama Y, Ogumi Z (2004) Solvated Li-ion transfer at interface between graphite and electrolyte. J Electrochem Soc 151:A1120-A1123. https://doi.org/10.1149/1.1763141

26. Hasegawa G, Kanamori K, Kannari N, Ozaki J, Nakanishi K, Abe T (2016) Studies on electrochemical sodium storage into hard carbons with binder-free monolithic electrodes. J Power Sources 318:41-48. https://doi.org/10.1016/j.jpowsour.2016.04.013

Publisher's Note Springer Nature remains neutral with regard to jurisdictional claims in published maps and institutional affiliations. 